\title{
Summer mortality of the blue mussel in eastern Canada: spatial, temporal, stock and age variation
}

\author{
A. L. Mallet, C. E. A. Carver, K. R. Freeman \\ Department of Fisheries and Oceans, 1707 Lower Water Street, Halifax, Nova Scotia, Canada B3J 2S7
}

\begin{abstract}
Survival of juvenile and adult blue mussels Mytilus edulis from several stocks was estimated at 3 sites in Prince Edward Island, Canada, from June 1987 to October 1988. In general, there was little evidence of spatial variability; the survival curves for a stock of a given age were similar across locations within a site and across sites. There were, however, significant differences in survival between years, stocks, and age groups. The cumulative survival was 0.77 for the period June to September 1987 , as compared to 0.85 for the same period in 1988. Of the 3 groups which exhibited poor survival $(0.59$ to $0.72)$ in 1987 , only one showed a similarly poor performance (0.66) in 1988. Overall, stock accounted for $28 \%$ of the variation in cumulative survival, whereas the contribution of the other main effects was negligible. Interaction terms which included Year, Stock, and Age accounted for $42 \%$ of the variance in mortality, suggesting a mutual dependence of these variables. Survival during the cold water months (October to May) was extremely high (>0.95) for all groups
\end{abstract}

\section{INTRODUCTION}

Several studies have provided valuable information on the growth of mussels under various environmental conditions in Atlantic Canada (Freeman 1974, MacLeod 1975, Freeman \& Dickie 1979, Mallet et al. 1987). Relatively little is known, however, about levels of natural mortality and their underlying causes, even though mortality contributes significantly to the variation in production observed among mussel farms (Mallet et al. 1987, Mallet \& Carver 1989). The present study focuses on the problem of 'summer mortality', or the die-off of significant numbers of mussels during the summer. Freeman \& Dickie (1979), working on the Atlantic coast, observed that both adult and juvenile mussels generally exhibited their highest mortality during the summer, with adults experiencing the greater losses. On the Canadian west coast, survival is high throughout the winter but decreases sharply in late spring; mussel populations older than 16 mo may exhibit mortalities in excess of $90 \%$ by the end of the summer (Heritage 1983, Emmett et al. 1987). Similar cases of summer mortality have been observed on the US west coast (Skidmore \& Chew 1985, Elston et al. 1988) and in Maine, USA (Incze et al. 1980). Although these numerous reports attest to the prevalence of this phenomenon, there is as yet no consensus as to the factors involved.
Diseases have been shown to account for some cases of high mortality in Mytilus edulis. $\mathrm{Li}$ \& Clyburne (1979) attributed mass mortalities of the blue mussel in Prince Edward Island (PEI), Canada, to an infectious organism, Labyrinthomyxa sp. Pathological investigations of emaciated or recently dead mussels in PEI during the summer 1987 did not, however, reveal any significant levels of infectious organisms in the tissues (G. Johnson, Atlantic Veterinary College, PEI, pers. comm. 1989). Another disease, described as a hemic disorder or a form of blood cancer, has also been linked to significant mortalities of mussels on the American west coast (Elston et al. 1988). Recent observations on mussels from PEI, however, did not reveal any indication of this disorder ( $G$. Johnson, Atlantic Veterinary College, PEI, pers. comm. 1989). Significant mussel mortalities in Atlantic Canada would therefore not appear to be disease-related.

One current working hypothesis is that summer mortality is physiologically mediated. Because of the close association between the timing of spawning and the onset of mortality, Emmett et al. (1987) suggested that summer mortality on the Canadian west coast is caused by reproductive stress. Worrall \& Widdows (1984) found a similar correlation between spawning and mortality in a Mytilus edulis population in Plymouth, England. They attributed the higher mortality observed in the larger size classes to their greater reproductive 
effort. Incze et al. (1980) acknowledged that gametogenesis may affect mortality, but noted that the major spawning peak was in May and that high mortalities were observed in September. Instead, the authors proposed that stressful environmental conditions, specifically a reduction in food ration at a time of high $\left(>20^{\circ} \mathrm{C}\right)$ water temperatures, were responsible for the high mortality.

The present study documents the variation in the survival curves of adult and juvenile mussels from several stocks of Mytilus edulis, transplanted to various mussel growing areas in eastern Canada. The major objective was to determine the relative importance of factors such as stock (i.e. genetics), age, and environmental conditions in determining mortality levels during the summer (June to September).

\section{MATERIALS AND METHODS}

Experimental design. Three sites were selected in Prince Edward Island, Canada for this study: Tracadie Bay, Boughton River and Murray River (Fig. 1). Adult (ca $22 \mathrm{mo}, 50$ to $60 \mathrm{~mm}$ ) and juvenile mussels (ca $10 \mathrm{mo}$, 30 to $40 \mathrm{~mm}$ ) were obtained from each site. Two of these stocks were indigenous to their collection sites (Boughton River and Tracadie Bay) whereas the Murray stock originated from St. Peters Bay, PEI. Mussels from each stock were placed at each of the 3 sites (i.e. reciprocal transplants)

To monitor mortality, we devised an experimental cally in the water, with six $10 \mathrm{~cm}$ pockets of nylon mesh $(7 \times 7 \mathrm{~mm})$ attached at each of 8 levels, or a total of 48 unit consisting of a $2 \mathrm{~m}$ line, weighted to hang verti-

individual pockets per line. One mussel was inserted in each pocket and the mesh was closed with an electrical cable tie. Each pocket was labelled with one of 6 coloured beads to allow individual identification of the mussels at each level.

To assess the variability in mortality, 72 experimental units were deployed at each site, i.e. 3 stocks by 2 age groups by 3 locations by 4 replicates, or a total of 3456 mussels per site or 192 per treatment. In general, the locations were chosen to cover the maximum range of environmental conditions; for example, one location was typically in the river mouth, another near the entrance to the sea, and the third midway between these extremes.

In 1987, the units were set up and transplanted in the last week of May. Two of these 3 sites (Tracadie and Boughton) were sampled weekly from June 1 to September 1 and thereafter twice a month until November 7, whereas Murray River was sampled on 8 occasions. In early November, we removed all the units except for the juveniles at the middle location in each site; these juveniles provided mortality data for the period of October 1987 to May 1988 and were monitored during the following summer as 'old' adults. New units were deployed in June 1988; the 'new' adults were obtained from juveniles which had been transplanted the previous summer. The 'new' juveniles were, however, obtained from their respective collection sites. In 1988, we used the same 3 stocks as before, but deployed units only at the middle location in each site, i.e. 3 stocks by 2 age groups by 4 replicates, or 1152 mussels per site. These 3 sites were visited every 2 wk from June 13 to August 27 and once a month thereafter until October 1, 1988.

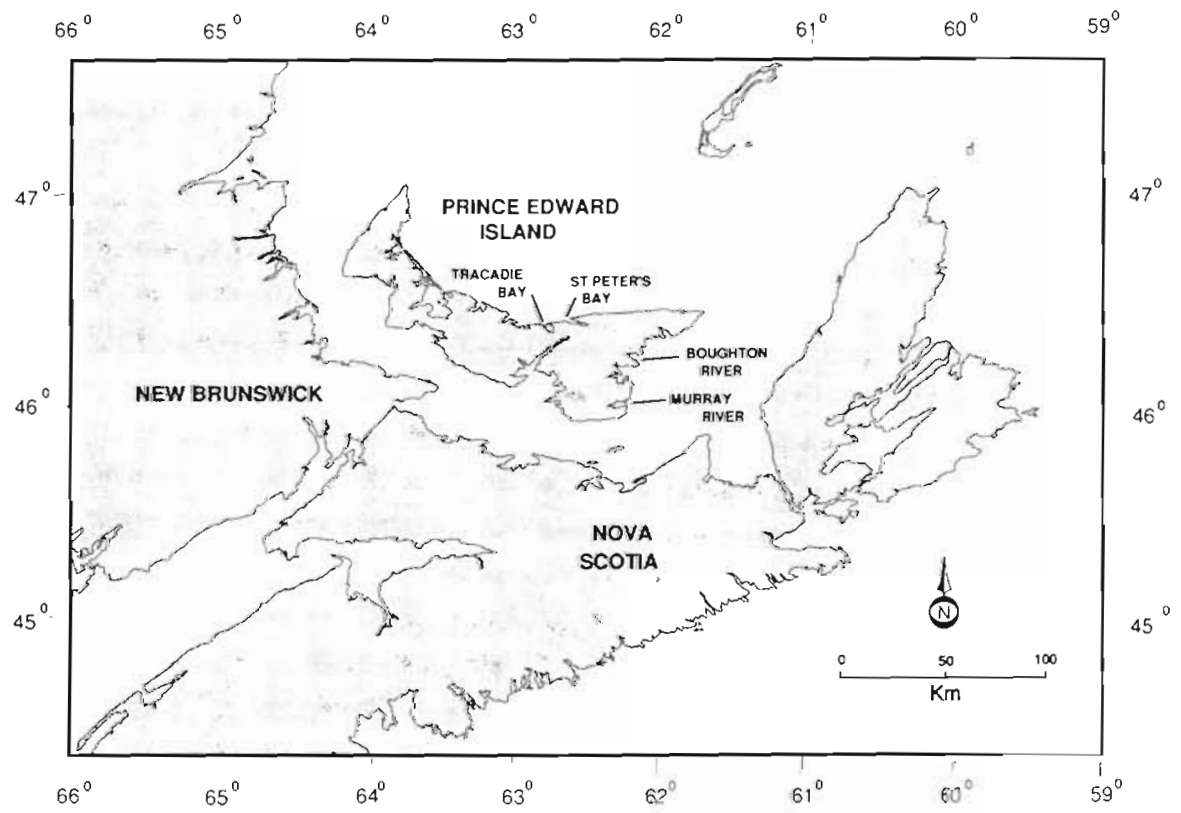

Fig. 1 Atlantıc Canada indicating the location of the 3 sites in Prince Edward Island (Tracadie, Boughton and Murrayl 
Statistical analysis. Survival functions were obtained for each mussel group at each location within a site and for each site over location in 1987 and 1988 (Lifetest procedure, SAS package, version 6.03). Equations to calculate the product-limit estimates of the survival density functions (i.e. the cumulative survival values in Tables 1, 2 and 4) and the corresponding standard errors are provided in Kalbfleish \& Prentice (1980). Rank statistics (Wilcoxon test) were used to test homogeneity of curves within the treatments (e.g. sites, locations, or stocks). The statistics are treated as a chisquare; they test whether the different curves have different shapes. It is therefore possible that treatments with identical cumulative survival can be statistically different given different temporal patterns. On the other hand, acceptance of the null hypothesis means that sampling points along 2 curves are statistically identical. The outcome of these independent tests were combined into an overall probability statistic following the approach proposed by Sokal \& Rolf (1969).

A variance component model was also used to partition the variance in the cumulative survival values between various main effects and high order interaction terms (Varcomp procedure, SAS package, version 6.03). Untransformed cumulative survival values were used because they conformed more closely to a normal distribution than did transformed arcsine, logarithmic, or reciprocal values. The general model was analysed

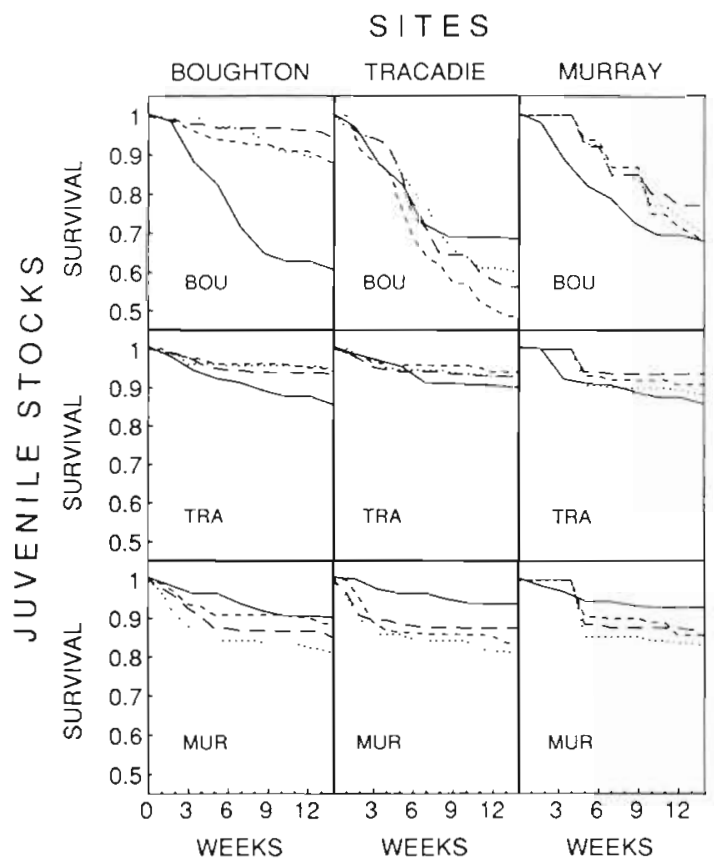

Fig. 2. Mytilus edulis. Mortality of juvenile mussels from $3 \mathrm{PEI}$ stocks (BOU, TRA, MUR) each grown at 3 sites (BOUGHTON. TRACADIE, MURRAY) in 1987 and 1988. Each site had 3 locations in 1987: (--) loc $1,(-\ldots)$ loc $2,(\cdots)$ loc 3. (-) Survival at 1 location in 1988 as a full factorial and included Year (1987 and 1988), Site (Boughton, Tracadie and Murray), Stock (Boughton, Tracadie and Murray) and Age (Juvenile and Adult). The Location effect was not included in the model because the survival curves were homogeneous across locations (see below).

\section{RESULTS}

Hereafter, the term 'stock group' refers to mussels from a given stock of a given age; for example, juvenile mussels from Tracadie would be labelled TRA ju. Survival curves from 1987 and 1988 for all stock groups at each location within each site are presented in Figs. 2 and 3. The survival curves for the Murray site in 1987 are irregular because of the less frequent sampling schedule. In general, the survival curves were less variable across sites and locations than among stock groups.

\section{Spatial effects}

The cumulative survival values averaged over the stock groups within a summer were very similar across locations and sites (Table 1) Rank statistics were used

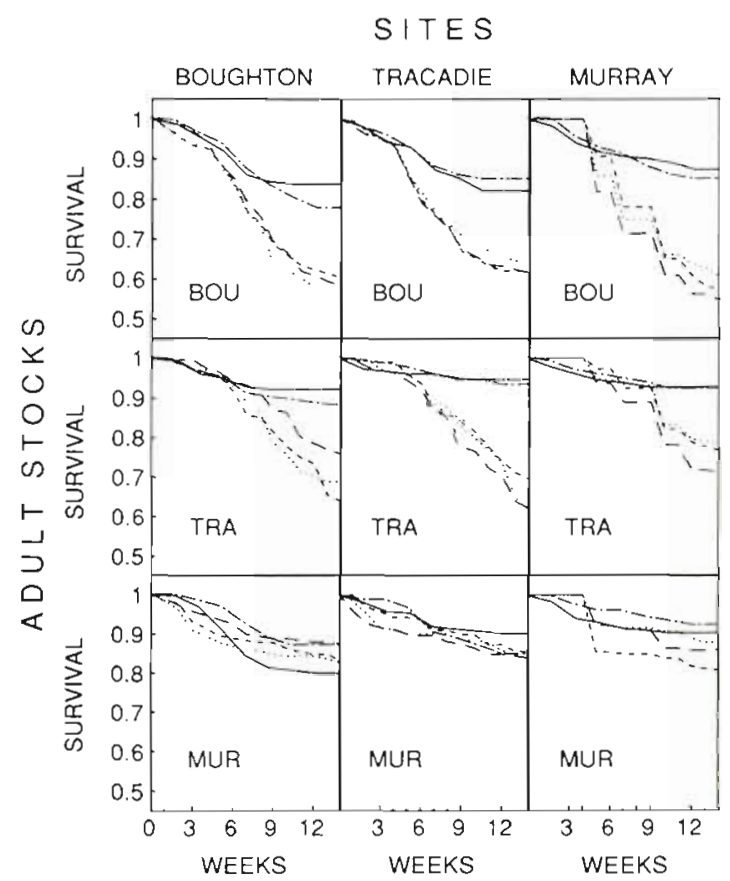

Fig. 3. Mytilus edulis. Mortality of adult mussels from 3 PEI stocks (BOU, TRA, MUR) each grown at 3 sites (BOUGHTON, TRACADIE, MURRAY) in 1987. Each site had 3 locations in 1987: (--) loc 1, (--) loc 2, (…) loc 3. (-) Adults placed in new units in the spring of 1988 ; (-..-) 'old' adults which were originally the experimental juveniles of 1987 
Table 1. Mytilus edulis. Cumulative survival (CUM) and 1 standard error (SE) pooled over all stock and age groups at the various locations from June to September in 1987 and 1988

\begin{tabular}{|llllll|}
\hline \multirow{2}{*}{ Site } & Location & \multicolumn{2}{c}{1987} & \multicolumn{2}{c|}{1988} \\
& & CUM & SE & CUM & SE \\
\hline \multirow{3}{*}{ Boughton } & River & 0.82 & 0.03 & & \\
& Middle & 0.80 & 0.03 & 0.82 & 0.04 \\
& Seaward & 0.78 & 0.03 & & \\
& River & 0.78 & 0.03 & & \\
Tracadie & Middle & 0.77 & 0.03 & 0.86 & 0.04 \\
& Seaward & 0.78 & 0.03 & & \\
& River & 0.74 & 0.03 & 0.86 & 0.04 \\
& Middle & 0.74 & 0.03 & & \\
& Seaward & 0.74 & 0.03 & & \\
\hline
\end{tabular}

Table 2. Mytilus edulis. Cumulative survival (CUM) and 1 standard error (SE) of the various stock groups pooled across sites and locations from June to September in 1987 and 1988

\begin{tabular}{|llllll|}
\hline \multirow{2}{*}{ Stock } & Age & \multicolumn{2}{c}{1987} & \multicolumn{2}{c|}{1988} \\
& & CUM & SE & CUM & SE \\
\hline \multirow{3}{*}{ Boughton } & Adult & 0.59 & 0.01 & 0.82 & 0.02 \\
& Juvenile & 0.72 & 0.03 & 0.66 & 0.02 \\
& Adult & 0.85 & 0.01 & 0.88 & 0.02 \\
Tracadie & Juvenile & 0.85 & 0.01 & 0.92 & 0.01 \\
& Adult & 0.70 & 0.01 & 0.91 & 0.01 \\
& Juvenile & 0.93 & 0.01 & 0.88 & 0.01 \\
\hline
\end{tabular}

to compare the equivalence of survival curves for each of the different stock groups across locations (Kalbfleisch \& Prentice 1980). Of the 18 Wilcoxon tests (3 sites by 6 groups), only 2 were statistically significant (Boughton site: TRA ad and BOU ju) and the combined probability was 0.08 . Because there was no significant variation in survival across locations, we opted to pool the curves for a given stock group across locations within sites.

The cumulative survival averaged over the stock groups showed differences among sites in 1987 but not in 1988 (Table 2). Rank statistics were also used to test for the homogeneity of survival curves of the various stock groups across sites. Two of the 12 tests $(1987 \times 6$ groups $+1988 \times 6$ groups) were significant, TRA ad and BOU ju in 1987 with an overall probability value of 0.02 . The survival curves of the various groups were very similar across sites, even those of the 1987 TRA ad group. The 1987 BOU ju group, however, did show substantial variation across sites (Fig, 2). We realized after the set-up period that the BOU ju group deployed at Boughton differed from the BOU ju group deployed at Tracadie and Murray in that they had not been sampled from the same location in Boughton, thereby causing problems in interpretation. Note that the $1988 \mathrm{BOU}$ ju group, which was collected at the same location as the high mortality group in 1987, had survival curves closely resembling those of the 1987 group. The removal of the 1987 BOU ju group from the test of the homogeneity of survival curves across sites gives an overall probability value of 0.10 ; furthermore, in an alternative analysis, the variance component model indicated that sites accounted for none of the variance in cumulative survival values (Table 3). We therefore chose to pool the survival curves for each stock across sites.

\section{Temporal effects}

Two major differences in the temporal pattern of mortality can be distinguished in this study. First, the level of mortality during the summer differed between years; overall survival was lower in $1987(0.77 \pm 0.01)$ than in $1988(0.85 \pm 0.01)(\mathrm{p}=0.0001)$. If we argue that

Table 3. Mytilus edulis. Variance component estimation of cumulative survival values indicating the percent of variance explained by various main effects and their interactions

\begin{tabular}{lrr}
\hline Source & df & Percent \\
\hline Year & 1 & 0.0 \\
Site & 2 & 0.0 \\
Stock & 2 & 28.1 \\
Age & 1 & 0.0 \\
Year $\times$ Site & 2 & 1.1 \\
Year $\times$ Stock & 2 & 0.0 \\
Year $\times$ Age & 1 & 0.0 \\
Stock $\times$ Age & 2 & 13.5 \\
Year $\times$ Site $\times$ Stock & 8 & 0.0 \\
Year $\times$ Site $\times$ Age & 4 & 0.0 \\
Year $\times$ Stock $\times$ Age & 2 & 15.1 \\
Year $\times$ Site $\times$ Stock $\times$ Age & 8 & 14.1 \\
Error & 251 & 28.1 \\
\hline
\end{tabular}

Table 4. Mytilus edulis. Cumulative survival (CUM) and 1 standard error (SE) of each stock at each site maintained at 1 location from October 1987 to May 1988

\begin{tabular}{|llll|}
\hline Site & Stock & CUM & SE \\
\hline \multirow{2}{*}{ Boughton } & Boughton & 0.97 & 0.00 \\
& Murray & 0.98 & 0.00 \\
& Tracadie & 0.98 & 0.00 \\
Murray & Boughton & 0.98 & 0.00 \\
& Murray & 0.99 & 0.00 \\
Tracadie & Tracadie & 0.99 & 0.00 \\
& Boughton & 0.98 & 0.00 \\
& Murray & 0.99 & 0.00 \\
& Tracadie & 0.96 & 0.00 \\
\hline
\end{tabular}


certain environmental factors are important in causing mortality, then differences in environmental conditions between years must be more important than differences among sites within a year, especially when sites are under the influence of similar regional factors. However, differences between years could also arise from the variable performance of different cohorts due to genetic variation. Second, the level of mortality in the summer differed from that during the colder months. Even though these winter survival values represent a longer time period, they were consistently higher than those for the summer months (Table 4). There was also no mortality variation among the stock groups during the colder months (Table 4). These observations suggest that most of the natural mortality of mussels held in suspended culture occurs over a relatively short time period during the summer.

\section{Stock and age effects}

Stock and age clearly had major effects on mortality; overall, these 2 factors and their interactions accounted for most of the variance in survival (Table 3 ). The cumulative survival values for each stock group, estimated over locations and sites, are presented in Table 2.

On average, juveniles showed higher survival than adults, particularly during the summer 1987 . Boughton juveniles, however, had the worst survival in both years $(<0.75)$, as compared to the Murray and Tracadie juveniles $(>0.85)$. The only obvious asymmetry in the survival curves between sites was displayed by the BOU ju group in 1987 for reasons explained previously. If aberrant stocks such as Boughton are excluded from the average, the expected annual cumulative survival for mussels less than 18 mo old would be greater than $85 \%$ (see also Mallet et al. 1987)

In 1987, Boughton and Tracadie adults showed relatively poor survival $(0.59$ and 0.70$)$ in contrast to those from the Murray River (0.85; Fig. 3 ). This divergence in survival among the adult groups began in early July and was confirmed by survival patterns in commercial operations. In 1988, the adult groups had survival values similar to those of the juveniles (0.82 to 0.91$)$. The longdash/short-dash curves in Fig. 2 represent those 1987 juvenile groups which were also followed as an 'old' adult group in 1988. These curves track very well with the 'new' adult groups (continuous line) of 1988. Both groups represented adult mussels from each stock that had been overwintered at each site. The purpose of this comparison was to remove differences in initial physiological conditions among stocks which may have been present in 1987, thereby confounding the stock component. However, the lack of variability among stocks and sites in 1988 did not allow the evaluation of that potential effect.

\section{DISCUSSION}

In this study, adult and juvenile mussels from several stocks were transplanted to various sites in Prince Edward Island, Canada. The experimental design allowed the evaluation of how differences in environmental conditions, either among locations within a site, among sites within a region, or between years can affect the survival of different mussel groups. This is in contrast with studies where causes of mortality are inferred from the performance of mussels in their natural environments (Worrall \& Widdows 1984, Elston et al. 1988), or where comparisons between environments or populations are based on performance of mussels from different sources, and where groups are not cross-classified between environments (Incze et al. 1980, Emmett et al. 1987).

Several hypotheses regarding the causes of mortality can be evaluated with this experimental design. First, if mortality levels are not genetically determined, then mussels from different genetic backgrounds would have similar survival curves when averaged over age and environment. Second, if agerelated factors, such as reproductive effort (Worrall \& Widdows 1984) do not affect mortality levels, then adults and juveniles should not exhibit different survival patterns. Third, if mortality levels are not influenced by small changes in environmental conditions, then similar survival curves would be expected for all groups at all locations.

The first hypothesis was rejected based on the observation that certain stocks did have different overall survival profiles when averaged over age and environment (i.e. Murray River vs Tracadie Bay). Furthermore, in some cases, adults and juveniles also exhibited different mortality levels (i.e. Tracadie Bay and Murray River) thus arguing against the second hypothesis of age-independent mortality. The suggestion that smallscale environmental differences did not affect survival was supported by the lack of mortality variation among stock groups within a given location and site. However, there were significant year-to-year variations in summer mortality which could indicate that large-scale, or annual, variations in environmental conditions can affect survival. This speculation is nonetheless confounded by the inevitable genetic variability of cohorts between years. Overall, we conclude that survival patterns in blue mussels were not explained by any one factor, but rather were determined by the interacting effects of stock, age and large-scale environmental factors. The relative importance of these interactions was evaluated in the variance component analysis (Table 3).

The importance of stock in this study supports the results of an earlier study by Mallet et al. (1987) where 
stock and its interactions accounted for $55 \%$ of the variance in mortality of 11 groups of juveniles each grown at 9 sites in Nova Scotia. Like the Boughton juveniles, 2 of these 11 stocks showed significantly lower survival during the summer, with mean values of 0.71 and 0.74 as compared to $>0.90$ for the other stocks. Such stocks which exhibit high juvenile mortality are likely in a minority and could represent populations that are adapted to a narrow range of environmental conditions, or perhaps populations that have a high incidence of genetic anomalies.

The relationship between spawning/reproductive effort and mortality is very difficult to ascertain from this study. First, even though there was a major spawning in 1988, no difference in survival was recorded between adults and juveniles, except for the Boughton stock. Second, although comparisons between adults and juveniles from the same stock demonstrated lower adult survival in 1987, there were several exceptions to this observation. Also, there is the problem of the time lag between spawning and mortality, as noted in Maine by Incze et al. (1980); in PEI, the major spawning occurs soon after ice break-up in May whereas the mortality is highest from early July to late August, a considerable lapse of time. It is therefore difficult to attribute the higher adult mortality solely to their greater reproductive effort (Worrall \& Widdows 1984) and we can argue that certain environmental conditions are necessary for the expression of the higher adult mortality.

The significantly higher mortality observed from June to September relative to the colder months suggests that mussels experience greater stress during the summer. The considerable stock and age as well as the individual variability in survival suggests that the thresholds exceeded or the functions impeded may differ among individuals of a population. This individual variability would not be evident under nonstressful conditions (e.g. during the cold water months), or when the lethal limits of the population are exceeded (e.g. temperatures greater than $28^{\circ} \mathrm{C}$ ).

\section{Expected mussel survival in suspended culture}

From this study and from Mallet et al. (1987), we can make certain generalizations about the expected mortality levels of mussels grown in suspended culture in eastern Canada. We assume that mussel survival generally follows a staircase function, with insignificant mortality in the cold months (i.e. water temperatures less than $10^{\circ} \mathrm{C}$ ), and higher mortality in the warm months (Fig. 4). We also suggest that the curves will vary depending on the stock involved and the environmental conditions present during any given year. Note that the curves were obtained by averaging actual survival data from this study.

In most instances, mortality patterns A1/A2 will prevail (Fig. 4); these curves are characterized by a cumulative juvenile survival greater than $84 \%$ up to 18 mo of age. At this time, one of 2 events can take place: the A.2 curve represents years of high adult mortality whereas the A1 curve describes years of low mortality. The conditions that may control which scenario (A1 or A2) develops will be analyzed in a subsequent paper. The other set of curves (B) represents the unusual case of high juvenile mortality. The second phase of that curve (B1 or B2) again depends on the presence or absence of high adult mortality. Based on this general model, we estimate that, depending on the particular stock and the environmental conditions, producers might expect to lose as little as $22 \%$, or as much as $54 \%$ of their crop to natural mortality.

Although the mussels grown in mesh pockets showed similar mortality levels to those in adjacent experimental sleeves, these values may actually underestimate losses in a commercial context. Mussels grown in sleeves are generally attached to each other rather than to the mesh; one death can thus result in the additional fall-off of several healthy mussels. Furthermore, high mortalities are often associated with a weakening of the byssal threads (Emmett et al. 1987), which in turn accentuates the risks of fall-off. This may explain why, even in years with only 30 to $40 \%$ natural mortality, one frequently finds sleeves where all mussels have been lost (Mallet pers. obs.)

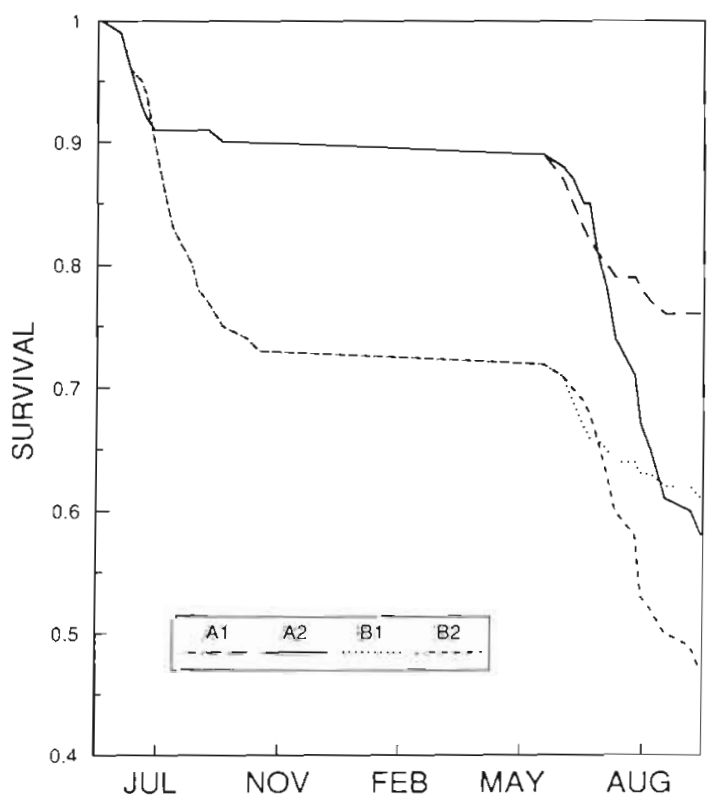

Fig. 4. Mytilus edulis. Predicted survival curves for adults and juveniles from PEI illustrating the impact of different mortality levels on survival over a standard 2 yr production cycle. See text for details on the legend 
Acknowledgements. The project was sponsored by the Unsolicited Proposal Program of the Department of Supply and Services for the Department of Fisheries and Oceans, Canada (Biological Sciences Branch, Scotia-Fundy; Science Branch, Gulf Region; and Habitat Ecology, Gulf Region) and the Nova Scotia Provincial Department of Fisheries. Technical assistance was provided by Simonne Duguay-Mallet, Scott Coffen, Geneviève Steele, and Lucia DiBacco. We thank Tim Lambert and Brian Irwin of Bedford Institute of Oceanography for equipment support. This work would not have been feasible without the cooperation of many people; in particular, the mussel producers - Wayne Somers, Ralph MacPherson, Joe Van den Bremt, and Roger Townshend. Special thanks must also go to David Scarratt and Jean Worms of DFO, and Marshall Giles, Irwin Judson, and Alan Morrison. We are grateful to everyone for their support.

\section{LITERATURE CITED}

Elston, R. A., Kent, M. L., Drum, A. S. (1988). Progression, lethality and remission of hemic neoplasia in the bay mussel Mytilus edulis. Dis. aquat. Org. 4: 135-142

Emmett, B., Thompson, K., Popham, J. D. (1987). The reproductive and energy storage cycles of two populations of Mytilus edulis (Linne) from British Columbia. J. Shellfish Res. 6: 29-36

Freeman, K. R. (1974). Growth, mortality, and seasonal cycle of Mytilus edulis in two Nova Scotian embayments. Tech. Rep. Fish. mar Serv. 500: $112 \mathrm{p}$.

Freeman, K. R., Dickie, L. M. (1979). Growth and mortality of

This article was presented by Dr G. C. Harding, Dartmouth, N.S. Canada the blue mussel (Mytilus edulis) in relation to environmental indexing. J. Fish Res. Bd Can. 36: 1238-1249

Heritage, G. D. (1983). A blue mussel (Mytilus edulis L.) culture pilot project in south coastal British Columbia. Tech. Rep. Fish. Aquat. Sci. Can. 1174: 27 p

Incze, L. S., Lutz, R. A., Watling, L. (1980). Relationships between effects of environmental temperature and seston on growth and mortality of Mytilus edulis in a temperate northern estuary. Mar. Biol. 57 147-156

Kalbfleisch, J. D., Prentice, R. L. (1980). The statistical analysis of failure time data. John Wiley and Sons, New York.

Li, M. F., Clyburne, S. (1979). Mortalities of blue mussel (Mytilus edulis) in Prince Edward Island. J. Invertebr. Path. 33: 108-110

MacLeod, L. L. (1975). Experimental blue mussel (Mytilus edulis) culture in Nova Scotia waters. Interim Rep. N.S. Dept Fish. I: $38 \mathrm{p}$

Mallet, A. L., Carver, C. E. A. (1989). Growth, mortality and secondary production in natural populations of the blue mussel Mytilus edulis. Can. J. Fish. Aquat. Sci. 46: 1154-1159

Mallet, A. L., Carver, C. E. A., Coffen, S. S., Freeman, K. R. (1987). Mortality variations in natural populations of the blue mussel, Mytilus edulis. Can. J. Fish. Aquat. Sci. 44: $1589-1594$

Skidmore, D. A., Chew, K. K. (1985). Mussel aquaculture in Puget Sound. Washington Sea Grant Rep. 85-4. University of Washington. Seattle

Sokal, R. R., Rohlf, F. J. (1969). Biometry. W. H. Freeman and Company, San Francisco, p. 621-624

Worrall, C. M., Widdows, J. (1984). Investigation of factors influencing mortality in Mytilus edulis L. Mar Biol. Lett. 5 $85-97$

Manuscript first received: January 9, 1990

Revised version accepted: July 12, 1990 